\title{
Comparing wind directions inferred from Martian dust devil tracks analysis with those predicted by the Mars Climate Database
}

\author{
T. Statella ${ }^{\text {a,* }}$, P. Pina ${ }^{b}$, E.A. Silva ${ }^{c}$, Ary Vinicius Nervis Frigeri ${ }^{a}$, Frederico Gallon Neto ${ }^{a}$ \\ a Instituto Federal de Educação, Ciência e Tecnologia de Mato Grosso - IFMT, 95 Zulmira Canavarro780025-200, Cuiabá, Brazil \\ ${ }^{\mathrm{b}}$ CERENA, Instituto Superior Técnico - IST, Universidade de Lisboa, Av. Rovisco Pais1049-001, Lisboa, Portugal \\ ${ }^{\mathrm{c}}$ Universidade Estadual Paulista, Faculdade de Ciências e Tecnologia - FCT, 305 Roberto Simonsen19060-900, Presidente Prudente, Brazil
}

\section{A R T I C L E I N F O}

Article history:

Received 7 December 2015

Received in revised form

7 June 2016

Accepted 21 July 2016

Available online 25 July 2016

\begin{abstract}
A B S T R A C T
We have calculated the prevailing dust devil tracks direction as a means of verifying the Mars Climate Database (MCD) predicted wind directions accuracy. For that purpose we have applied an automatic method based on morphological openings for inferring the prevailing tracks direction in a dataset comprising 200 Mars Orbiter Camera (MOC) Narrow Angle (NA) and High Resolution Imaging Science Experiment (HiRISE) images of the Martian surface, depicting regions in the Aeolis, Eridania, Noachis, Argyre and Hellas quadrangles. The prevailing local wind directions were calculated from the MCD predicted speeds for the WE and SN wind components. The results showed that the MCD may not be able to predict accurately the locally dominant wind direction near the surface. In adittion, we confirm that the surface wind stress alone cannot produce dust lifting in the studied sites, since it never exceeds the threshold value of $0.0225 \mathrm{Nm}^{-2}$ in the MCD.
\end{abstract}

(c) 2016 Elsevier Ltd. All rights reserved.

\section{Introduction}

Dust devils are small whirlwinds made visible by entrained dust and sand. They are upward moving, spiraling flows caused by heating of near-surface air by insolation (Balme and Greeley, 2006). Dust devils activity is easily identified in remotely sensed images by the tracks they often leave behind. Dust devil tracks are albedo patterns on planetary surfaces that result from the removal of particles by the presence of a dust devil to expose an underlying surface with a different albedo. On Mars, dust devil tracks densities were shown to change with the time of the year, suggesting that dust devil activity also depends on the season of the year (Thomas et al., 2003; Whelley and Greeley, 2006). Those albedo features tend to fade with time, which is attributed to the deposition of dust (Malin and Edgett, 2001; Balme et al., 2003). In a period of a few months ( 2 to 4 months) old tracks can be recovered by dust and replaced by new tracks (Statella et al., 2015).

Important information that can be obtained by the analysis of the tracks is the trajectory of the vortices, which can be used to infer the prevailing wind orientation near the surface, as dust devils are typically thought to move, on average, in the direction of the dominant wind (Rennó et al., 1998). The inference of the wind

\footnotetext{
* Corresponding author.

E-mail addresses: thiago.statella@cba.ifmt.edu.br (T. Statella), ppina@tecnico.ulisboa.pt (P. Pina), erivaldo@fct.unesp.br (E.A. Silva), aryviniciusnf@gmail.com (A.V. Nervis Frigeri), fredgneto@gmail.com (F.G. Neto).
}

direction based on aeolian features is one of the few procedures for verifying circulation models of the Martian atmosphere. As a plethora of orbital images of the surface of Mars has been made available, automatic methods can be developed and applied to detect (Statella et al., 2012) and measure the orientation of dust devil tracks.

The prevailing direction of the wind at specific locations on the surface of Mars for a certain solar longitude can be estimated from extractions of the Mars Climate Database (MCD). Such extractions can then be compared to the prevailing direction of dust devil tracks previously detected (Statella et al., 2012) in Mars Orbiter Camera (MOC) Narrow Angle (NA) and High Resolution Imaging Science Experiment (HiRISE) images at the same locations. From the detected dust devil tracks we could estimate the prevailing track direction for each image by using the Directional Morphological Openings by Linear Structuring Elements, as proposed by Statella et al. (2014). The prevailing direction of dust devil tracks for each scene has been compared to the MCD extractions in order to find out if the MCD information could be used to describe local wind patterns on the surface of Mars.

\section{Image Dataset}

The image dataset from which we have detected the dust devil tracks was made up of 124 images: 75 MOC narrow angle panchromatic band and 49 HiRISE red band from Aeolis, Argyre, 


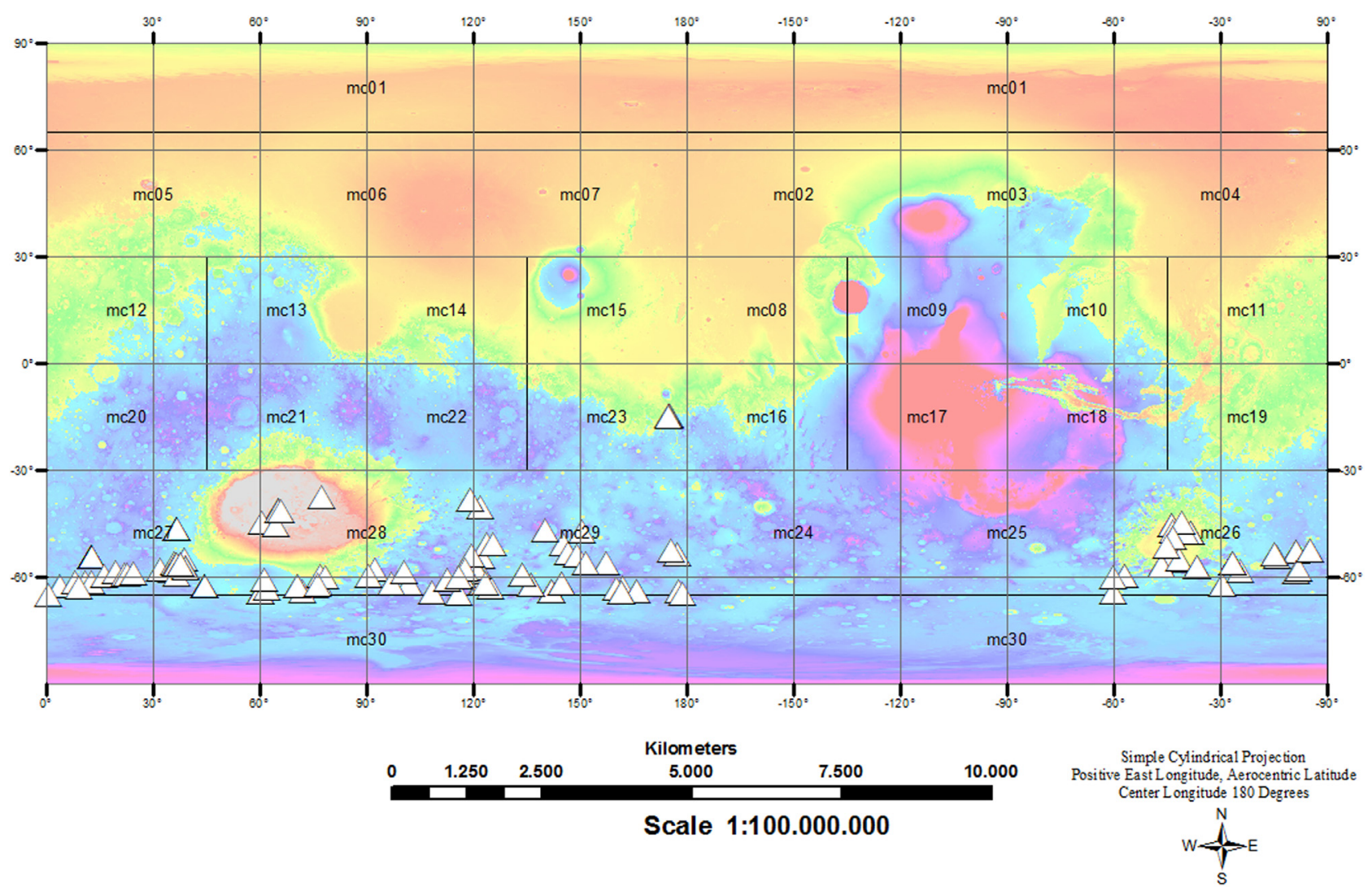

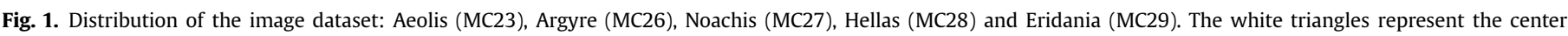
coordinates of the original scenes. Image credits: R.K. Hayward, K.F. Mullins, L.K. Fenton, T.M. Hare, T.N. Titus, M.C. Bourke, A. Colaprete, P.R. Christensen.

Noachis, Hellas and Eridania quadrangles defined by Mars Charts (MC, as defined by the USGS mapping quadrangles) 23,26 , 27, 28 and 29, respectively. By having detected the dust devil tracks we mean that the image dataset was formed by a set of binary images in which pixels belonging to tracks have been labeled with value 1 (white) and pixels not belonging to tracks have been labeled with value 0 (black). The detection procedure has been fully described in Statella et al. (2012). The spatial resolution of HiRISE images was either $0.25 \mathrm{~m}$ ( $\sim 90 \%$ of the images) or $0.50 \mathrm{~m}$ while the MOC spatial resolution varied from $1.43 \mathrm{~m}$ to $8.75 \mathrm{~m}$ (mean $\sim 5 \mathrm{~m}$ ). Some of them were cropped into several regions of interest, enlarging the image dataset to 200 images (90 MOC and 110 HiRISE). Fig. 1 shows the distribution of the initial set (before cropping procedure) of 124 images (white triangles) according to their center coordinates in the planetocentric coordinate system. The base map is the Mars Orbiter Laser Altimeter (MOLA) topography layer of the Mars Global Digital Dune Database. In order to infer the prevailing wind direction from dust devil tracks we have used one of the methods proposed by Statella et al. (2014), namely, the Directional Morphological Openings by Linear Structuring Elements method. The input for this method is a binary image showing detected dust devil tracks in white and the background in black. Dust devil tracks had been previously detected in the 200 images using the method proposed by Statella et. al (2012), with a global accuracy of $92 \% \pm 5 \%$.

\section{Inferring the prevailing wind direction from dust devil tracks}

Dust devils are typically thought to move, on average, in the direction of the prevailing surface wind (Rennó et al.,1998). The prevailing wind direction can then be inferred by calculating the prevailing dust devil tracks direction in orbital images. For that purpose we have adopted one of the methods developed by Statella et al. (2014), namely, the Directional Morphological Openings by Linear Structuring Elements. This method is based on Mathematical Morphology (MM), a theory developed by Georges Matheron and Jean Serra in the 1960s, which is highly adequate to deal with the geometric features of structures. A few definitions of the theory, useful to fully explain the Directional Morphological Openings by Linear Structuring Elements method, are given below.

Let us first define a digital image as follows: Let $E$ be a nonempty set of adjacent squares arranged in rows and columns, forming a rectangular surface. Let $K$ be a set of gray levels. A gray level image is a mapping $E \rightarrow K$. Usually, $K$ belongs to the interval $[0, K]$ in $Z$ with $E \in Z^{2}$.

Then we can define the major mathematical morphology transformations, Erosion and Dilation:

Let $B$ be a subset from $Z^{2}, B \subset E$. The Erosion (Soille, 2004), $\varepsilon$, of an image $f$ by $B$ is the minimum of the translation of $f$ by the vectors $-b$ of $B$. $B$ is called Structuring Element (SE).

$\varepsilon_{B}(f)=\underset{b \in B}{\wedge} f_{-b}$

The Dilation (Soille, 2004), $\delta$, of $f$ by a SE $B$ is the maximum of the translation of $f$ by the vectors $b$ of $B$.

$\delta_{B}(f)=\underset{b \in B}{\vee} f_{b}$

The structuring element $B$ is a completely defined and known (size and shape) set which is compared, in a transformation, to the image unknown set. The result of this transformation allows us to evaluate the unknown set. Based on Erosion and Dilation transformations we can define the morphological Opening. The Opening, $\gamma$, of $f$ by a structuring element $B$ is the erosion of $f$ by $B$ followed by a dilation by $B$ transposed (Soille, 2004): 


$$
\gamma_{B}(f)=\delta_{B} *\left[\varepsilon_{B}(f)\right]
$$

A morphological Opening will remove from the image all the regions of the image whose shape and size do not fully contain the structuring element. Linear Structurig Elements (LSEs) can be arranged in several orientations so that a morphological Opening can provide information about the directions of binary sets in an digital image. Let us now define a set of directions $\alpha \in Z^{+}$, measured clockwise from North in steps of $n$ degrees. For $n=15^{\circ}$, we then have the set of directions $\alpha=\left\{0^{\circ}, 15^{\circ}, ., 345^{\circ}\right\}$. The direction opposed to $\alpha$ is denoted $\alpha^{\prime}$, so if $\alpha=0^{\circ}$ then $\alpha^{\prime}=180^{\circ}$. The path in the direction $\alpha$ is defined as the union of the radii of the LSE in the directions $d$ and $d^{\prime}$. As an example, the path in the direction $45^{\circ}$ is composed by the radii (with origin in a given pixel $p$ ) oriented to $45^{\circ}$ and $225^{\circ}$ (one can notice that the path in the direction $225^{\circ}$ is identical to the path in the direction $45^{\circ}$, as both paths share the same radii). Now it is possible to define a family $L_{\alpha, \lambda}$ (with direction $\alpha$ and size $\lambda$ ) of line SEs whose paths are oriented in the directions $\alpha=\left\{0^{\circ}, 15^{\circ}, ., 165^{\circ}\right\}$. As examples, LSEs with sizes $\lambda=1$ in the directions $0^{\circ}, 45^{\circ}, 90^{\circ}$ and $135^{\circ}$ are:

$B_{0}=\left[\begin{array}{lll}0 & 1 & 0 \\ 0 & 1 & 0 \\ 0 & 1 & 0\end{array}\right], B_{45}=\left[\begin{array}{lll}0 & 0 & 1 \\ 0 & 1 & 0 \\ 1 & 0 & 0\end{array}\right]$,
$B_{90}=\left[\begin{array}{lll}0 & 0 & 0 \\ 1 & 1 & 1 \\ 0 & 0 & 0\end{array}\right], B_{135}=\left[\begin{array}{lll}1 & 0 & 0 \\ 0 & 1 & 0 \\ 0 & 0 & 1\end{array}\right]$

The choice for the angular steps of $15^{\circ}$ derives from the digital approximations performed when building linear structuring elements in a square digital grid, that is, increasing the number of angular steps after this level of detail would not provide much more meaningful information.

The main advantage of this method is the high capability of directional Openings to estimate the prevailing orientation of dust devil tracks as Mathematical Morphology operators are crafted on the analysis of the geometry and topology of object features.

After applying Openings with LSEs of size $\lambda$ in the directions $\alpha=$ $\left\{0^{\circ}, 15^{\circ}, ., 165^{\circ}\right\}$, the prevailing direction of the tracks is assumed to be the one in which the Opening has removed less pixels than in any other directions, that is, the direction where the structuring element better fits the tracks. The size $\lambda$ of the LSEs varied from scene to scene (but, for each image, the size was fixed) according to the maximum width of the tracks in each scene. The width of the tracks in each scene is calculated as described in Statella et al. (2016). When plotting the results in a direction diagram, where each wing of the diagram represents the amount of pixels removed by the Opening, one should look for the smallest wing to determine
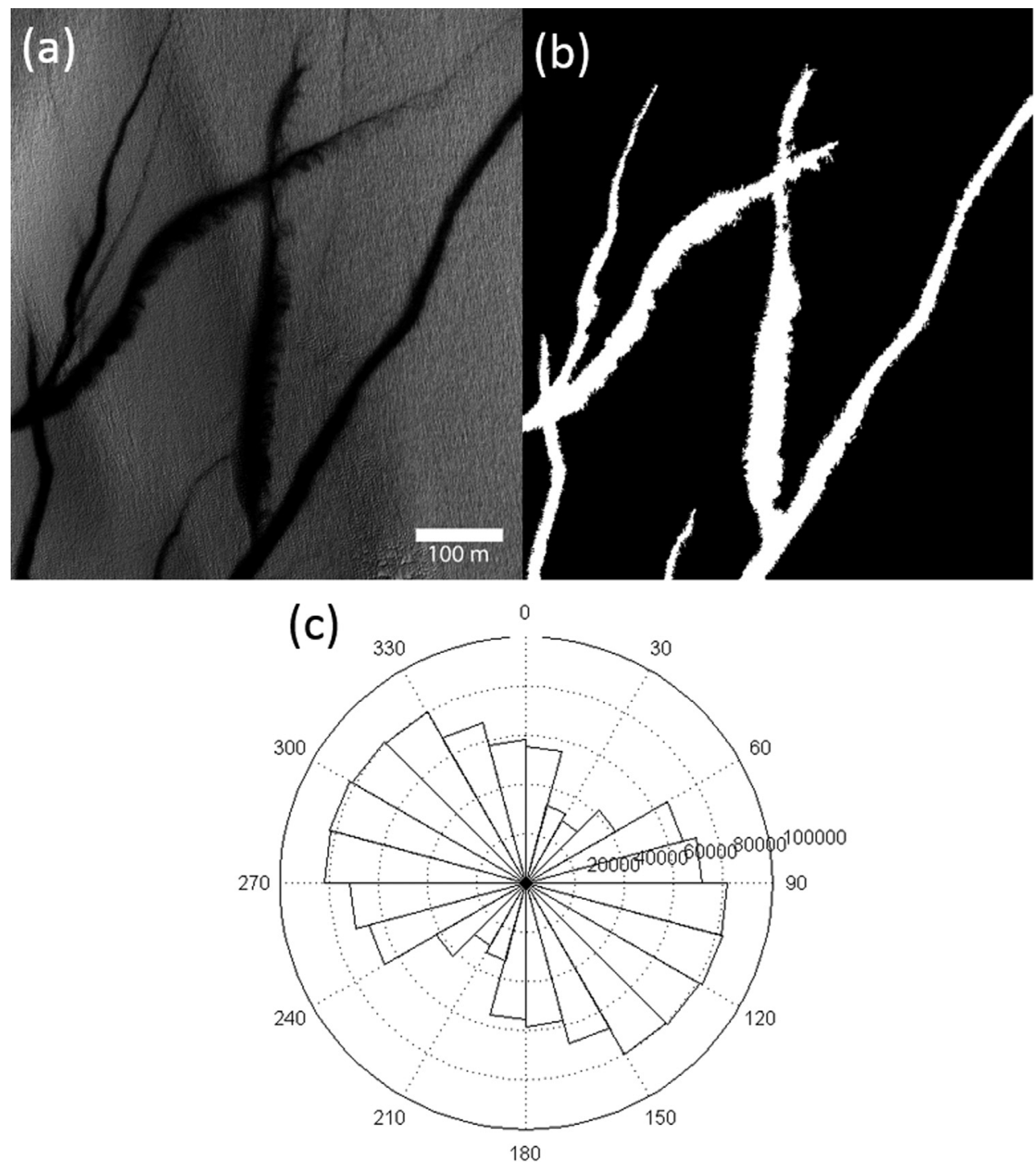

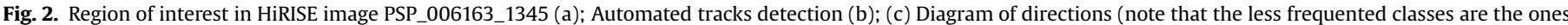
less modified by the LSE and thus the ones corresponding to the prevailing orientions). [Original image credits: NASA/JPL/University of Arizona]. 

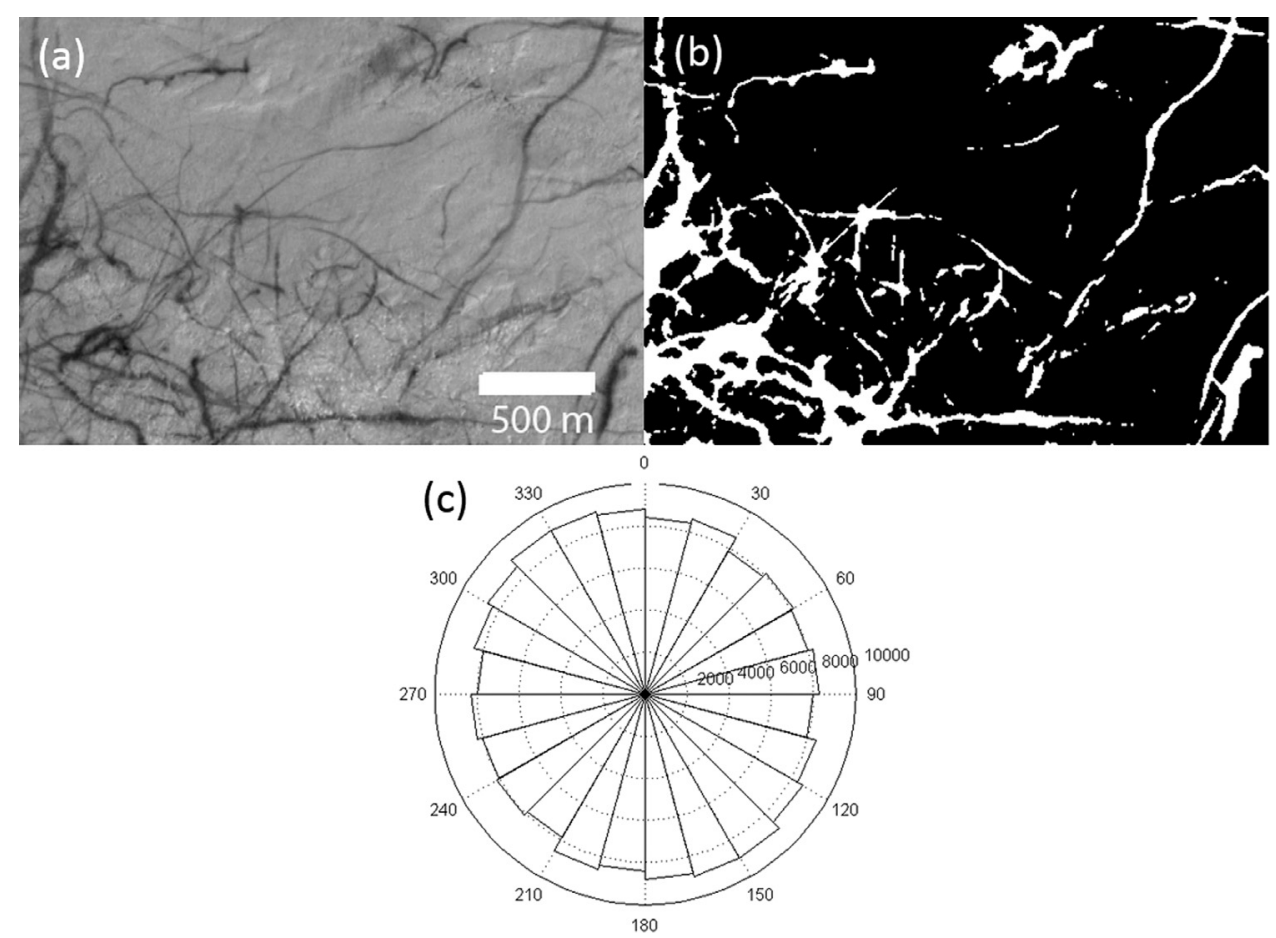

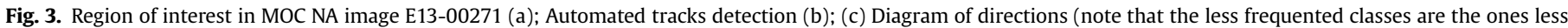
modified by the LSE and thus the ones corresponding to the prevailing orientions). [Original image credits: NASA/JPL/MSSS].

the prevailing direction. Consider, as an example, a region of interest of the image HiRISE PSP_006163_1345 from Argyre quadrangle shown in Fig. 2a. The binary image shown in Fig. $2 \mathrm{~b}$ is the result of the dust devil tracks detection, which has been used as input for estimating the prevailing direction of the winds in that scene. In Fig. 2c we show the direction diagram for that image. The prevailing wind direction inferred from this image by the presented method is the less frequented one, that is, $30^{\circ}-210^{\circ}$.

Fig. 3 shows another example, this time for the MOC NA image E13-00271, also from Argyre quadrangle. As we can observe in Fig. 3a, tracks do not seem to follow any preferential direction as they do in HiRISE image PSP_006163_1345. Thus, we cannot infer, visually, any preferable direction. Nevertheless, after applying the directional morphological openings we could estimate the prevailing direction as being $\sim 30^{\circ}-210^{\circ}$.

\section{Results}

Morphological Openings with LSEs oriented in the directions $\alpha$ $=\left\{0^{\circ}, 15^{\circ}, ., 165^{\circ}\right\}$ have been applied to the image dataset in order to automatically infer the prevailing dust devil tracks direction. The size $\lambda$ of the LSEs varied from scene to scene (but, for each image, the size was fixed) according to the maximum width of the tracks in each scene (this procedure has been adopted in order to avoid a possible influence of the width of the tracks in the results). Tracks width had been calculated as described in Statella et al. (2016). We show the results per region and per solar longitude $L_{s}$ (in angular intervals of $30^{\circ}$ ) in the Tables $1-5$, where it can be seen the varation in dust devil tracks directon with the season of the year. The solar longitude is the Mars-Sun angle, measured from the Northern Hemisphere spring equinox where $L_{s}=0^{\circ}$. Intervals of $30^{\circ}$ in solar longitude represent the passage of a martian month. Therefore, for the Northern Hemisphere we have: from $L_{s}=0^{\circ}$ to $90^{\circ}$ the spring season (autumn for the Southern Hemisphere), from $L_{s}=90^{\circ}$ to $180^{\circ}$ the summer season (winter for the Southern Hemisphere), from $L_{s}=180^{\circ}$ to $270^{\circ}$ the autumn season (spring
Table 1

Prevailing dust devil tracks directions for Aeolis quadrangle.

\begin{tabular}{llll}
\hline Solar Longitude $L_{S}$ [deg.] & Season & $\mathbf{N}^{\circ}$ of images & $\begin{array}{l}\text { Prevailing direction } \\
\text { [deg.] }\end{array}$ \\
\hline $\mathbf{0 - 3 0}$ & Autumn & 1 & $120-300$ \\
$\mathbf{1 2 0 - 1 5 0}$ & Winter & 1 & $105-285$ \\
$\mathbf{2 4 0 - 2 7 0}$ & Spring & 2 & $105-285 / 45-225$ \\
$\mathbf{3 3 0 - 3 6 0}$ & Summer & 1 & $120-300$ \\
\hline
\end{tabular}

Table 2

Prevailing dust devil tracks directions for Argyre quadrangle.

\begin{tabular}{llll}
\hline Solar Longitude $L_{s}$ [deg.] & Season & $\mathbf{N}^{\circ}$ of images & $\begin{array}{l}\text { Prevailing direction } \\
\text { [deg.] }\end{array}$ \\
\hline $\mathbf{2 4 0 - 2 7 0}$ & & & $45-225$ \\
$\mathbf{2 7 0 - 3 0 0}$ & Spring & 7 & $0-180$ \\
$\mathbf{3 0 0 - 3 3 0}$ & Summer & 7 & $30-210$ \\
$\mathbf{3 3 0 - 3 6 0}$ & Summer & 15 & $45-225$ \\
\hline
\end{tabular}

Table 3

Prevailing dust devil tracks directions for Noachis quadrangle.

\begin{tabular}{llll}
\hline Solar Longitude $L_{S}$ [deg.] & Season & $\mathbf{N}^{\circ}$ of images & $\begin{array}{l}\text { Prevailing direction } \\
\text { [deg.] }\end{array}$ \\
\hline $\mathbf{1 8 0 - 2 1 0}$ & Spring & 3 & $120-300 / 0-180 / 60-240$ \\
$\mathbf{2 1 0 - 2 4 0}$ & Spring & 1 & $90-270$ \\
$\mathbf{2 4 0 - 2 7 0}$ & Spring & 7 & $165-345$ \\
$\mathbf{2 7 0 - 3 0 0}$ & Summer & 15 & $165-345$ \\
$\mathbf{3 3 0 - 3 6 0}$ & Summer & 13 & $15-195$ \\
\hline
\end{tabular}

for the Southern Hemisphere) and from $L_{S}=270^{\circ}$ to $360^{\circ}$ the winter season (summer for the Southern Hemisphere). The prevailing direction for a given interval in solar longitude, for example $0^{\circ}-30^{\circ}$, has been adopted as being the modal value among all directions measured in all scenes whose solar longitudes fall in that interval. 
Table 4

Prevailing dust devil tracks directions for Hellas quadrangle.

\begin{tabular}{|c|c|c|c|}
\hline Solar Longitude $L_{s}[\mathrm{deg}]$. & Season & $\mathrm{N}^{\circ}$ of images & $\begin{array}{l}\text { Prevailing direction } \\
\text { [deg.] }\end{array}$ \\
\hline $240-270$ & Spring & 3 & $165-345 / 90-270 / 135-193$ \\
\hline $270-300$ & Summer & 11 & $90-270$ \\
\hline $300-330$ & Summer & 25 & $30-210$ \\
\hline $330-360$ & Summer & 1 & $135-315$ \\
\hline
\end{tabular}

Table 5

Prevailing dust devil tracks directions for Eridania quadrangle.

\begin{tabular}{llll}
\hline Solar Longitude $L_{s}$ [deg.] & Season & $\mathbf{N}^{\circ}$ of images & $\begin{array}{l}\text { Prevailing direction } \\
\text { [deg.] }\end{array}$ \\
\hline $\mathbf{2 4 0 - 2 7 0}$ & Spring & 14 & $120-300$ \\
$\mathbf{2 7 0 - 3 0 0}$ & Summer & 18 & $0-180$ \\
$\mathbf{3 0 0 - 3 3 0}$ & Summer & 11 & $75-255 / 90-270 / 105-285$ \\
$\mathbf{3 3 0 - 3 6 0}$ & Summer & 2 & $0-180$ \\
\hline
\end{tabular}

In Table 1 we can see that the prevailing tracks directions follow a pattern SE-NW for solar longitudes intervals $0^{\circ}-30^{\circ}$ (autumn), $120^{\circ}-270^{\circ}$ (winter/spring) and $120^{\circ}-300^{\circ}$ (winter/spring/ summer). For solar longitudes ranging from $240^{\circ}$ to $270^{\circ}$ (spring) we found two dominant directions, which are $105^{\circ}-285^{\circ}$ and $45^{\circ}-$ $225^{\circ}$. The large difference between those two directions is believed to have been caused by the fact that we had only two images from Aeolis quadrangle.

For Argyre quadrangle, whose results are shown in Table 2, we have found a pattern NE-SW for the orientation of the tracks. For Noachis quadrangle, as shown in Table 3, we have found different results for the prevailing tracks directions among the solar longitude intervals. For solar longitudes ranging from $240^{\circ}$ to $270^{\circ}$ (spring) and from $270^{\circ}$ to $300^{\circ}$ (summer) a pattern SE-NW can be seen. From $180^{\circ}$ to $210^{\circ}$ (spring) the dominant tracks directions do not show a preferable direction and from $210^{\circ}$ to $240^{\circ}$ (spring), tracks directions inferred from the one image in that interval followed the E-W orientation.

In Table 4, the prevailing dust devil tracks directions calculated for Hellas quadrangle were $90^{\circ}-270^{\circ}$ (E-W) for images acquired during the solar longitudes from $270^{\circ}$ to $300^{\circ}$ (summer), $30^{\circ}-310^{\circ}$ for images whose solar longitudes fall in the interval $300^{\circ}$ to $330^{\circ}$ (summer) and $135^{\circ}-315^{\circ}$ for the one image whose solar longitude falls in the interval $330^{\circ}$ to $360^{\circ}$ (summer). For the $240^{\circ}-270^{\circ}$ (spring) solar longitude interval the images showed no unique modal value. Instead, the tracks are mainly oriented in three directions.

In Table 5 we show the results for Eridania quadrangle. For solar longitudes ranging from $270^{\circ}$ to $300^{\circ}$ (summer) and from $330^{\circ}$ to $360^{\circ}$ (summer) the tracks follow a E-W pattern. The prevailing directon changes for $120^{\circ}-300^{\circ}$ for images in the interval $240^{\circ}-270^{\circ}$ (spring) and we found three modal values for images with solar longitudes ranging from $300^{\circ}$ to $330^{\circ}$ (summer).

In Tables 6-10 we show the directions calculated for each image of the quadrangles Aeolis, Argyre, Noachis, Hellas and Eridania, the CPBL height, the solar longitude and the local time acquisition for each image and the directions of the winds predicted by the MCD. The MCD is a database of atmospheric statistics compiled from the Global Climate Model (GCM) and respective numerical simulations of the Martian atmosphere (Forget et al., 1999; Lewis et al., 1999). It was developed by the Laboratoire de Météorologie Dynamique (LMD, Paris), Atmospheric, Oceanic and Planetary Physics group (AOPP, Oxford), Department of Physics and Astronomy (The Open University) and Instituto de Astrofísica de Andalucía (IAA, Granada) with the support of the European Space Agency and the Centre National d'Etudes Spatiales and the outputs provided by the MCD are based on large-scale climatological means.

The extractions have been done according to the solar longitude, acquisition date and time, latitude and longitude of each scene, at three different altitudes from surface: $50 \mathrm{~m}, 1000 \mathrm{~m}$ and at the Convective Planetary Boundary Layer ( $\mathrm{CPBL}$ ) height. The Martian Planetary Boundary Layer (PBL) is the portion of the atmosphere closest to the surface, within which interactions between the atmosphere and the surface itself are active. In practice, this represents the lowest portion of the atmosphere, within which surface-driven intense convection may take place, forming convective plumes and vortices during the day (Haberle et al., 1993; Hinson et al., 2008; Petrosyan et al., 2011).

The height of the PBL and, in particular, the height of daytime $\mathrm{CPBL}$, is a key quantity describing the vigor of convective activity, that changes over the surface according to the local thickness of the atmosphere layer. Examples of estimated PBL heights inferred from lander measurements, from heights of convective clouds, from temperature profiles or radio occultation are given by Fenton and Lorenz (2015) and a more extensive study is given by Hinson et al. (2008).

We have chosen the altitudes in our extractions from the MCD so that they match the lower CPBL, which is $1000 \mathrm{~m}$ from the surface, and the upper CPBL limit, which has been obtained from the MCD for each image center coordinates. Fenton and Lorenz (2015) have performed a study on Amazonis Planitia and have found out that the CPBL thickness can be estimated as being $\sim 5$ times the median of the active dust devil plumes, after analyzing MRO CTX images. As we are rather working with dust devil tracks instead of plumes, we cannot infer such relationship and, therefore, we have decided to consider the upper limit of the CPBL in the experments. In addition, we have run the predictions at $50 \mathrm{~m}$ from the surface in order to see if the wind directions could differ significantly from those in the CPBL and if the portion of the atmosphere closer to the surface could play a more dominant role in the directions of the dust devils. For the experiments we have used the MCD version 5.2 and we have adopted the climatology average solar dust scenario for it is the most representative of a standard condition. Running the extractions with Mars Years (MY) scenarios corresponding to the acquisition date of the images in a sample of the dataset did not show significant (i. e., were not larger than the $15^{\circ}$ of the precision of the method used to calculate directions in the images) differences when compared with the climatology

Table 6

Comparison between calculated prevailing wind direction and predicted wind direction for Aeolis.

\begin{tabular}{|c|c|c|c|c|c|c|c|}
\hline \multirow[t]{2}{*}{ ID } & \multirow[t]{2}{*}{$L_{s}[$ deg.] } & \multirow[t]{2}{*}{ Local Time } & \multirow[t]{2}{*}{ Calculated [deg.] } & \multirow[t]{2}{*}{ CPBL $[\mathrm{m}]$} & \multicolumn{3}{|c|}{ Predicted [deg.] } \\
\hline & & & & & $50 \mathrm{~m}$ & $1000 \mathrm{~m}$ & CPBL \\
\hline E16-01962 & 18.77 & $13: 39$ & $120-300$ & 4500 & $45-225$ & $45-225$ & $30-210$ \\
\hline R02-00357 & 134.17 & $14: 40$ & $105-285$ & 5500 & $30-210$ & $15-195$ & $0-180$ \\
\hline PSP_003834_1650 & 242.6 & $15: 14$ & $120-300$ & 6300 & $90-270$ & $90-270$ & $75-255$ \\
\hline R08-02402 & 249.25 & $14: 27$ & $105-285$ & 6300 & $105-285$ & $90-270$ & $90-270$ \\
\hline R13-01467 & 331.03 & $13: 31$ & $120-300$ & 5600 & $60-240$ & $60-240$ & $45-225$ \\
\hline
\end{tabular}


Table 7

Comparison between calculated prevailing wind direction and predicted wind direction for Argyre.

\begin{tabular}{|c|c|c|c|c|c|c|c|}
\hline \multirow[t]{2}{*}{ ID } & \multirow[t]{2}{*}{$L_{s}[$ deg.] } & \multirow[t]{2}{*}{ Local Time } & \multirow[t]{2}{*}{ Calculated [deg.] } & \multirow[t]{2}{*}{ CPBL [m] } & \multicolumn{3}{|c|}{ Predicted [deg.] } \\
\hline & & & & & $50 \mathrm{~m}$ & $1000 \mathrm{~m}$ & CPBL \\
\hline M10-01206 & 260.85 & $14: 09$ & $165-345$ & 4800 & $120-300$ & $120-300$ & $0-180$ \\
\hline S08-02952 & 257.68 & $14: 24$ & $90-270$ & 6400 & $30-210$ & $15-195$ & $30-210$ \\
\hline R08-02621_P1 & 250.90 & $14: 40$ & $0-180$ & 6300 & $45-225$ & $30-210$ & $30-210$ \\
\hline R08-02621_P2 & 250.90 & $14: 40$ & $120-300$ & 6300 & $45-225$ & $30-210$ & $30-210$ \\
\hline S08-03151 & 259.03 & $14: 18$ & $45-225$ & 5000 & $0-180$ & $0-180$ & $0-180$ \\
\hline ESP_012927_1245 & 256.30 & $15: 24$ & $60-240$ & 4500 & $75-255$ & $75-255$ & $60-240$ \\
\hline ESP_013204_1260 & 270.00 & $15: 11$ & $45-225$ & 4600 & $90-270$ & $75-255$ & $75-255$ \\
\hline S10-01582 & 297.27 & $13: 52$ & $75-255$ & 6200 & $165-345$ & $165-345$ & $0-180$ \\
\hline S10-01598 & 297.32 & $13: 46$ & $15-195$ & 4600 & $30-210$ & $30-210$ & $30-210$ \\
\hline ESP_013310_1200_P1 & 275.10 & $15: 07$ & $165-345$ & 6200 & $0-180$ & $0-180$ & $165-345$ \\
\hline ESP_013310_1200_P2 & 275.10 & $15: 07$ & $75-255$ & 6200 & $0-180$ & $0-180$ & $165-345$ \\
\hline ESP_013626_1245 & 290.40 & $15: 02$ & $120-300$ & 4700 & $120-300$ & $105-285$ & $105-345$ \\
\hline ESP_013520_1180_P1 & 285.30 & $14: 58$ & $120-300$ & 6400 & $120-300$ & $120-300$ & $165-345$ \\
\hline ESP_013520_1180_P2 & 285.30 & $14: 58$ & $105-285$ & 6400 & $120-300$ & $120-300$ & $165-345$ \\
\hline E13-00271_P1 & 320.78 & $13: 28$ & $30-210$ & 5600 & $120-300$ & $120-300$ & $150-330$ \\
\hline E13-00271_P2 & 320.78 & $13: 28$ & $75-255$ & 5600 & $120-300$ & $120-300$ & $150-330$ \\
\hline M14-00175_P1 & 329.22 & $13: 22$ & $0-180$ & 4200 & $30-210$ & $30-210$ & $75-255$ \\
\hline M14-00175_P2 & 329.22 & $13: 22$ & $105-285$ & 4200 & $30-210$ & $30-210$ & $75-255$ \\
\hline M12-02214 & 305.76 & $13: 30$ & $15-198$ & 4300 & $60-240$ & $60-240$ & $60-240$ \\
\hline ESP_013996_1155 & 307.60 & $14: 42$ & $30-210$ & 5700 & $90-270$ & $90-270$ & $135-315$ \\
\hline ESP_014049_1200 & 310.10 & $14: 38$ & $45-225$ & 5700 & $45-225$ & $45-225$ & $15-195$ \\
\hline ESP_014259_1230_P1 & 319.50 & $14: 32$ & $0-180$ & 4600 & $135-315$ & $120-300$ & $90-270$ \\
\hline ESP_014259_1230_P2 & 319.50 & $14: 32$ & $30-210$ & 4600 & $135-315$ & $120-300$ & $90-270$ \\
\hline PSP_005596_1245 & 326.20 & $14: 28$ & $90-270$ & 4200 & $90-270$ & $90-270$ & $90-270$ \\
\hline PSP_005397_1270_P1 & 317.40 & $14: 29$ & $60-240$ & 6000 & $105-285$ & $105-285$ & $135-315$ \\
\hline PSP_005397_1270_P2 & 317.40 & $14: 29$ & $105-285$ & 6000 & $105-285$ & $105-285$ & $135-315$ \\
\hline PSP_005397_1270_P3 & 317.40 & $14: 29$ & $75-255$ & 6000 & $105-285$ & $105-285$ & $135-315$ \\
\hline PSP_005397_1270_P4 & 317.40 & $14: 29$ & $75-255$ & 6000 & $105-285$ & $105-285$ & $135-315$ \\
\hline PSP_005397_1270_P5 & 317.40 & $14: 29$ & $90-270$ & 6000 & $105-285$ & $105-285$ & $135-315$ \\
\hline E14-00400_P1 & 339.47 & $13: 26$ & $0-180$ & 4100 & $30-210$ & $30-210$ & $75-255$ \\
\hline E14-00400_P2 & 339.47 & $13: 26$ & $135-315$ & 4100 & $30-210$ & $30-210$ & $75-255$ \\
\hline E14-00400_P3 & 339.47 & $13: 26$ & $0-180$ & 4100 & $30-210$ & $30-210$ & $75-255$ \\
\hline R13-02691 & 334.68 & $13: 45$ & $0-180$ & 5300 & $105-285$ & $105-285$ & $120-300$ \\
\hline PSP_005820_1320_P1 & 335.70 & $14: 25$ & $30-210$ & 4200 & $30-210$ & $30-210$ & $60-240$ \\
\hline PSP_005820_1320_P2 & 335.70 & $14: 25$ & $45-225$ & 4200 & $30-210$ & $30-210$ & $60-240$ \\
\hline PSP_005820_1320_P3 & 335.70 & $14: 25$ & $45-225$ & 4200 & $30-210$ & $30-210$ & $60-240$ \\
\hline PSP_005820_1320_P4 & 335.70 & $14: 25$ & $45-225$ & 4200 & $30-210$ & $30-210$ & $60-240$ \\
\hline PSP_005820_1320_P5 & 335.70 & $14: 25$ & $45-225$ & 4200 & $30-210$ & $30-210$ & $60-240$ \\
\hline PSP_005820_1320_P6 & 335.70 & $14: 25$ & $30-210$ & 4200 & $30-210$ & $30-210$ & $60-240$ \\
\hline PSP_005820_1320_P7 & 335.70 & $14: 25$ & $165-345$ & 4200 & $30-210$ & $30-210$ & $60-240$ \\
\hline PSP_005820_1320_P8 & 335.70 & $14: 25$ & $45-225$ & 4200 & $30-210$ & $30-210$ & $60-240$ \\
\hline PSP_005846_1235_P1 & 336.80 & $14: 29$ & $75-255$ & 5400 & $105-285$ & $105-285$ & $150-330$ \\
\hline PSP_005846_1235_P2 & 336.80 & $14: 29$ & $75-255$ & 5400 & $105-285$ & $105-285$ & $150-330$ \\
\hline PSP_005846_1235_P3 & 336.80 & $14: 29$ & $105-285$ & 5400 & $105-285$ & $105-285$ & $150-330$ \\
\hline PSP_005846_1235_P4 & 336.80 & $14: 29$ & $105-285$ & 5400 & $105-285$ & $105-285$ & $150-330$ \\
\hline PSP_005846_1235_P5 & 336.80 & $14: 29$ & $90-270$ & 5400 & $105-285$ & $105-285$ & $150-330$ \\
\hline PSP_005846_1235_P6 & 336.80 & $14: 29$ & $105-285$ & 5400 & $105-285$ & $105-285$ & $150-330$ \\
\hline PSP_005846_1235_P7 & 336.80 & $14: 29$ & $105-285$ & 5400 & $105-285$ & $105-285$ & $150-330$ \\
\hline PSP_005846_1235_P8 & 336.80 & $14: 29$ & $0-180$ & 5400 & $105-285$ & $105-285$ & $150-330$ \\
\hline PSP_005846_1235_P9 & 336.80 & $14: 29$ & $45-225$ & 5400 & $105-285$ & $105-285$ & $150-330$ \\
\hline PSP_005846_1235_P10 & 336.80 & $14: 29$ & $105-285$ & 5400 & $105-285$ & $105-285$ & $150-330$ \\
\hline PSP_005846_1235_P11 & 336.80 & $14: 29$ & $75-255$ & 5400 & $105-285$ & $105-285$ & $150-330$ \\
\hline PSP_005846_1235_P12 & 336.80 & $14: 29$ & $60-240$ & 5400 & $105-285$ & $105-285$ & $150-330$ \\
\hline PSP_005846_1235_P13 & 336.80 & $14: 29$ & $90-270$ & 5400 & $105-285$ & $105-285$ & $150-330$ \\
\hline PSP_005846_1235_P14 & 336.80 & $14: 29$ & $120-300$ & 5400 & $105-285$ & $105-285$ & $150-330$ \\
\hline PSP_005846_1235_P15 & 336.80 & $14: 29$ & $165-345$ & 5400 & $105-285$ & $105-285$ & $150-330$ \\
\hline PSP_005846_1235_P16 & 336.80 & $14: 29$ & $30-210$ & 5400 & $105-285$ & $105-285$ & $150-330$ \\
\hline PSP_005846_1235_P17 & 336.80 & $14: 29$ & $120-300$ & 5400 & $105-285$ & $105-285$ & $150-330$ \\
\hline PSP_005846_1235_P18 & 336.80 & $14: 29$ & $45-225$ & 5400 & $105-285$ & $105-285$ & $150-330$ \\
\hline PSP_005846_1235_P19 & 336.80 & $14: 29$ & $60-240$ & 5400 & $105-285$ & $105-285$ & $150-330$ \\
\hline PSP_005846_1235_P20 & 336.80 & $14: 29$ & 15-195 & 5400 & $105-285$ & $105-285$ & $150-330$ \\
\hline PSP_005846_1235_P21 & 336.80 & $14: 29$ & $90-270$ & 5400 & $105-285$ & $105-285$ & $150-330$ \\
\hline PSP_005846_1235_P22 & 336.80 & $14: 29$ & 15-195 & 5400 & $105-285$ & $105-285$ & $150-330$ \\
\hline PSP_006163_1345_P1 & 349.80 & $14: 28$ & $30-210$ & 4200 & $0-180$ & $0-180$ & $15-195$ \\
\hline PSP_006163_1345_P2 & 349.80 & $14: 28$ & $30-210$ & 4200 & $0-180$ & $0-180$ & 15-195 \\
\hline PSP_006163_1345_P3 & 349.80 & $14: 28$ & $45-225$ & 4200 & $0-180$ & $0-180$ & 15-195 \\
\hline PSP_006163_1345_P4 & 349.80 & $14: 28$ & $60-240$ & 4200 & $0-180$ & $0-180$ & $15-195$ \\
\hline PSP_006176_1225_P1 & 350.40 & $14: 34$ & $135-315$ & 4200 & $105-285$ & $105-285$ & $90-270$ \\
\hline PSP_006176_1225_P2 & 350.40 & $14: 34$ & $120-300$ & 4200 & $105-285$ & $105-285$ & $90-270$ \\
\hline PSP_006176_1225_P3 & 350.40 & $14: 34$ & $150-330$ & 4200 & $105-285$ & $105-285$ & $90-270$ \\
\hline PSP_005780_1215 & 334.00 & $14: 30$ & $105-285$ & 5500 & $105-285$ & $105-285$ & $105-285$ \\
\hline
\end{tabular}


Table 8

Comparison between calculated prevailing wind direction and predicted wind direction for Noachis.

\begin{tabular}{|c|c|c|c|c|c|c|c|}
\hline \multirow[t]{2}{*}{ ID } & \multirow[t]{2}{*}{$L_{s}[$ deg.] } & \multirow[t]{2}{*}{ Local Time } & \multirow[t]{2}{*}{ Calculated [deg.] } & \multirow[t]{2}{*}{ CPBL $[\mathbf{m}]$} & \multicolumn{3}{|c|}{ Predicted [deg.] } \\
\hline & & & & & $50 \mathrm{~m}$ & $1000 \mathrm{~m}$ & CPBL \\
\hline PSP_002548_1255_P1 & 181.80 & $16: 00$ & $120-300$ & 2600 & $60-240$ & $75-255$ & $75-255$ \\
\hline PSP_002548_1255_P2 & 181.80 & $16: 00$ & $60-240$ & 2600 & $60-240$ & $75-255$ & $75-255$ \\
\hline PSP_002548_1255_P3 & 181.80 & $16: 00$ & $120-300$ & 2600 & $60-240$ & $75-255$ & $75-255$ \\
\hline PSP_003326_1255 & 217.80 & $15: 53$ & $75-255$ & 4900 & $75-255$ & $75-255$ & $105-285$ \\
\hline PSP_004038_1255 & 257.70 & $15: 20$ & $75-255$ & 6300 & $135-315$ & $135-315$ & $75-255$ \\
\hline PSP_004249_1255 & 263.10 & $15: 11$ & $15-195$ & 6600 & $135-315$ & $135-315$ & $60-240$ \\
\hline R0903467 & 267.72 & $14: 22$ & $135-315$ & 6100 & $165-345$ & $165-345$ & $150-330$ \\
\hline S09-01660_P1 & 269.93 & $14: 12$ & $165-345$ & 6200 & $165-345$ & $165-345$ & $150-330$ \\
\hline S09-01660_P2 & 269.93 & $14: 12$ & $165-345$ & 6200 & $165-345$ & $165-345$ & $150-330$ \\
\hline S09-00929_P1 & 265.39 & $14: 17$ & $0-180$ & 6100 & $165-345$ & $165-345$ & $150-330$ \\
\hline S09-00929_P2 & 265.39 & $14: 17$ & $165-345$ & 6100 & $165-345$ & $165-345$ & $150-330$ \\
\hline ESP_013321_1175 & 275.70 & $15: 08$ & $135-315$ & 6000 & $150-330$ & $150-330$ & $120-300$ \\
\hline ESP_013557_1245 & 287.10 & $14: 52$ & $165-345$ & 6400 & $165-345$ & $165-345$ & $135-315$ \\
\hline E11-01722 & 287.99 & $13: 52$ & $30-210$ & 5900 & $165-345$ & $165-345$ & $0-180$ \\
\hline E11-03103 & 293.62 & $13: 48$ & $0-180$ & 5700 & $165-345$ & $165-345$ & $0-180$ \\
\hline E11-00747 & 284.82 & $13: 55$ & $30-210$ & 6100 & $150-330$ & $150-330$ & $0-180$ \\
\hline E11-01129 & 286.08 & $13: 53$ & $90-270$ & 6400 & $150-330$ & $150-330$ & $0-180$ \\
\hline E11-01527 & 287.34 & $13: 51$ & $60-240$ & 6400 & $150-330$ & $150-330$ & $165-345$ \\
\hline E11-03844 & 297.33 & $13: 43$ & $30-210$ & 5900 & $150-330$ & $150-330$ & $165-345$ \\
\hline E11-02963 & 292.98 & $13: 46$ & 15-195 & 6100 & $150-330$ & $150-330$ & $165-345$ \\
\hline E11-00582 & 284.17 & $13: 54$ & $45-225$ & 6400 & $150-330$ & $150-330$ & $165-345$ \\
\hline E11-01314 & 286.68 & $13: 51$ & $0-180$ & 6300 & $165-345$ & $165-345$ & $165-345$ \\
\hline R10-04224 & 285.72 & $14: 08$ & $165-345$ & 6100 & $150-330$ & $150-330$ & $165-345$ \\
\hline R10-02844 & 281.23 & $14: 08$ & $165-345$ & 6300 & $165-345$ & $165-345$ & $150-330$ \\
\hline R10-04196 & 285.67 & $14: 03$ & $30-210$ & 6400 & $165-345$ & $165-345$ & $150-330$ \\
\hline R10-00382 & 272.25 & $14: 17$ & $150-330$ & 6200 & $165-345$ & $165-345$ & $150-330$ \\
\hline R11-03714 & 304.30 & $13: 50$ & $15-195$ & 5500 & $165-345$ & $150-330$ & $135-315$ \\
\hline PSP_005238_1255 & 310.30 & $14: 33$ & $120-300$ & 6400 & $120-300$ & $135-315$ & $150-330$ \\
\hline PSP_005383_1255 & 316.80 & $14: 26$ & $0-180$ & 6100 & $120-300$ & $120-300$ & $150-330$ \\
\hline PSP_005528_1255 & 323.20 & $14: 20$ & $105-285$ & 5900 & $105-285$ & $120-300$ & $135-315$ \\
\hline ESP_013992_1170_P1 & 307.50 & $14: 41$ & $0-180$ & 5600 & $150-330$ & $150-330$ & $150-330$ \\
\hline ESP_013992_1170_P2 & 307.50 & $14: 41$ & 15-195 & 5600 & $150-330$ & $150-330$ & $150-330$ \\
\hline ESP_013992_1170_P3 & 307.50 & $14: 41$ & $30-210$ & 5600 & $150-330$ & $150-330$ & $150-330$ \\
\hline ESP_014020_1150 & 308.70 & $14: 42$ & $30-210$ & 5300 & $165-345$ & $165-345$ & $165-345$ \\
\hline ESP_014322_1215 & 322.30 & $14: 38$ & 15-195 & 5300 & $135-315$ & $135-315$ & $120-300$ \\
\hline PSP_005659_1335_P1 & 328.90 & $14: 24$ & 15-195 & 6000 & $75-255$ & $75-255$ & $90-270$ \\
\hline PSP_005659_1335_P2 & 328.90 & $14: 24$ & $0-180$ & 6000 & $75-255$ & $75-255$ & $90-270$ \\
\hline PSP_005659_1335_P3 & 328.90 & $14: 24$ & $0-180$ & 6000 & $75-255$ & $75-255$ & $90-270$ \\
\hline E12-01041 & 306.48 & $13: 38$ & $150-330$ & 5400 & $165-345$ & $165-345$ & $150-330$ \\
\hline
\end{tabular}

average solar dust scenario. As the MYs scenarios are produced from irregularly observations, which are subsequently gridded into a regular network by kriging, and as we had no means to assess and compare the accuracy of the MYs scenarios against the average solar dust scenario, we have run the experiments with this last scenario. Regarding the time used for the extractions, we have chosen it to match each image acquisition time. As we cannot know the exact time of dust devil formation, some approximated time value should be adopted. In general, the image acquisition time is very close the peak time of the formation of the convective plumes, therefore, we have adopted that time for the extractions from the MCD. Experiments carried out on a subsample set of images showed that extractions from an interval of \pm 1 hour centered at the time of acquisition did not result in differences larger than the precision of the method used for calculating the wind direction from the tracks.

Information about winds from the MCD is based on large-scale (computed for regions of a few degrees in latitude and longitude) climatological means, therefore, the locally prevailing winds that drive the dust devil can be expected to be influenced by regional and local conditions which may not be resolved at the grid scale of the MCD.

In the extractions, the MCD provides wind speeds defined by two components: the meridional SN wind (positive when oriented from south to north) and the zonal WE wind (positive when oriented from west to east) in $\mathrm{m} / \mathrm{s}$. The resulting wind direction has been defined as:

$\alpha=\tan ^{-1}(W E / S N)$

for $W E>0$ and $S N>0$. If $W E>0$ and $S N<0$, then $\alpha=180^{\circ}-$ I $\alpha \mid$; if $W E<0$ and $S N<0$, then $\alpha=180^{\circ}+|\alpha|$; and if $W E<0$ and $S N>0$, then $\alpha=360^{\circ}-|\alpha|$.

Albeit MOC NA and HiRISE images are projected in Sinusoidal and Equirectangular systems, respectively, which are not conformal projections, the errors involved in estimating directions from that remotely sensed data can be considered negletable in the present case. Statella (2015) showed that the maximum angular distortion for a typical HiRISE image is $\sim 0.6^{\circ}$. And for a typical MOC NA image it is $\sim 0.02^{\circ}$, even though meridians are not straight lines in the Sinusoidal projection.

For the comparison between the wind directions inferred from dust devil tracks and the predicted wind directions from the MCD we have considered a tolerance of $15^{\circ}$ (which was the angular step used in the directions measurements) for the differences obtained. Therefore, when the difference between the calculated dust devil track prevailing direction and the MCD predicted wind direction differed only by one angular bin class $\left(15^{\circ}\right)$, we considered both directions as being the same.

In Table 6, where we compare the wind directions inferred from dust devil tracks with the predicted wind directions for Aeolis quadrangle, only $20 \%$ of the values agree for the three altitude values. The results obtained for the other 4 quadrangles 
Table 9

Comparison between calculated prevailing wind direction and predicted wind direction for Hellas.

\begin{tabular}{|c|c|c|c|c|c|c|c|}
\hline \multirow[t]{2}{*}{ ID } & \multirow[t]{2}{*}{$L_{s}[\mathrm{deg}]}$. & \multirow[t]{2}{*}{ Local Time } & \multirow[t]{2}{*}{ Calculated [deg.] } & \multirow[t]{2}{*}{ CPBL $[\mathrm{m}]$} & \multicolumn{3}{|c|}{ Predicted [deg.] } \\
\hline & & & & & $50 \mathrm{~m}$ & $1000 \mathrm{~m}$ & CPBL \\
\hline E10-00012_C1 & 263.49 & $14: 17$ & $165-345$ & 5400 & $120-300$ & $120-300$ & $120-300$ \\
\hline E10-00578_C & 266.02 & $14: 18$ & $150-330$ & 6700 & $15-195$ & $0-180$ & $0-180$ \\
\hline S09-01218_C & 267.20 & $14: 17$ & $135-315$ & 7300 & $165-345$ & $0-180$ & $0-180$ \\
\hline E10-02468_C3 & 273.23 & $13: 58$ & $90-270$ & 4800 & $60-240$ & $60-240$ & $60-240$ \\
\hline E10-02820_C & 274.51 & $13: 56$ & $60-240$ & 4900 & $60-240$ & $60-240$ & $60-240$ \\
\hline E11-01296_C & 286.63 & $13: 53$ & $165-345$ & 6300 & $150-330$ & $150-330$ & $150-330$ \\
\hline E11-00727_C1 & 284.72 & $13: 57$ & $45-225$ & 5800 & $150-330$ & $150-330$ & $165-345$ \\
\hline E11-00727_C2 & 284.72 & $13: 57$ & $0-180$ & 5800 & $150-330$ & $150-330$ & $165-345$ \\
\hline E11-00727_C3 & 284.72 & $13: 57$ & $150-330$ & 5800 & $150-330$ & $150-330$ & $165-345$ \\
\hline E10-04932_C & 282.14 & $13: 57$ & $105-285$ & 6200 & $105-285$ & $105-285$ & $165-345$ \\
\hline E10-01933_C & 271.23 & $14: 07$ & $0-180$ & 6600 & $120-300$ & $120-300$ & $150-330$ \\
\hline E11-00173_C & 282.75 & $14: 00$ & $60-240$ & 7200 & $165-345$ & $165-345$ & $165-345$ \\
\hline E10-02444_C & 273.12 & $14: 02$ & $150-330$ & 6600 & $45-225$ & $45-225$ & $15-195$ \\
\hline E11-01270_C & 286.53 & $13: 51$ & $45-225$ & 7000 & $0-180$ & $0-180$ & $15-195$ \\
\hline E12-01277_C1 & 307.63 & $13: 27$ & $75-255$ & 4800 & $60-240$ & $60-240$ & $45-225$ \\
\hline E12-01277_C2 & 307.63 & $13: 27$ & $75-255$ & 4800 & $60-240$ & $60-240$ & $45-225$ \\
\hline E12-01277_C3 & 307.63 & $13: 27$ & $105-285$ & 4800 & $60-240$ & $60-240$ & $45-225$ \\
\hline E12-01752_C & 310.02 & $13: 36$ & $30-210$ & 5200 & $150-330$ & $150-330$ & $150-330$ \\
\hline E12-00190_C1 & 302.08 & $13: 30$ & $30-210$ & 5800 & $165-345$ & $165-345$ & $120-300$ \\
\hline E12-00190_C2 & 302.08 & $13: 30$ & $120-300$ & 5800 & $165-345$ & $165-345$ & $120-300$ \\
\hline E1301622_C & 329.28 & $13: 23$ & $75-255$ & 4200 & $60-240$ & $60-240$ & $60-240$ \\
\hline E13-00975_C & 325.28 & $13: 23$ & $60-240$ & 4300 & $60-240$ & $60-240$ & $60-240$ \\
\hline R12-01589_C & 316.21 & $13: 50$ & $105-185$ & 5100 & $150-330$ & $150-330$ & $150-330$ \\
\hline R1201264_C & 314.38 & $13: 49$ & $15-195$ & 6300 & $150-330$ & $150-330$ & $165-345$ \\
\hline ESP_014399_1220_C & 325.60 & $14: 34$ & $75-255$ & 5700 & $120-300$ & $120-300$ & $120-300$ \\
\hline ESP_014176_1155_C1 & 315.80 & $14: 34$ & $165-345$ & 5100 & $150-330$ & $150-330$ & $150-330$ \\
\hline ESP_014176_1155_C2 & 315.80 & $14: 34$ & $15-195$ & 5100 & $150-330$ & $150-330$ & $150-330$ \\
\hline ESP_014176_1155_C3 & 315.80 & $14: 34$ & $45-225$ & 5100 & $150-330$ & $150-330$ & $150-330$ \\
\hline ESP_014176_1155_C4 & 315.80 & $14: 34$ & $150-330$ & 5100 & $150-330$ & $150-330$ & $150-330$ \\
\hline ESP_014176_1155_C5 & 315.80 & $14: 34$ & $150-330$ & 5100 & $150-330$ & $150-330$ & $150-330$ \\
\hline ESP_014176_1155_C6 & 315.80 & $14: 34$ & $0-180$ & 5100 & $150-330$ & $150-330$ & $150-330$ \\
\hline ESP_014108_1200_C1 & 312.70 & $14: 37$ & $30-210$ & 6800 & $150-330$ & $150-330$ & $150-330$ \\
\hline ESP_014108_1200_C2 & 312.70 & $14: 37$ & $120-300$ & 5100 & $150-330$ & $150-330$ & $150-330$ \\
\hline ESP_014070_1170_C & 311.00 & $14: 43$ & $90-270$ & 5500 & $120-300$ & $120-300$ & $135-315$ \\
\hline ESP_014069_1180_C & 311.00 & $14: 39$ & $30-210$ & 6700 & $135-315$ & $135-315$ & $150-330$ \\
\hline ESP_014056_1180_C & 310.40 & $14: 40$ & $75-255$ & 6800 & $120-300$ & $120-300$ & $150-330$ \\
\hline ESP_014004_1180_C & 308.00 & $14: 41$ & $120-300$ & 5600 & $120-300$ & $120-300$ & $150-330$ \\
\hline ESP_013991_1160_C & 307.40 & $14: 43$ & $120-300$ & 5500 & $135-315$ & $135-315$ & $150-330$ \\
\hline ESP_013965_1165_C & 306.20 & $14: 43$ & $150-330$ & 5600 & $135-315$ & $135-315$ & $150-330$ \\
\hline PSP_006264_1420_C & 359.90 & $14: 28$ & $45-235$ & 4000 & $45-225$ & $45-225$ & $45-225$ \\
\hline
\end{tabular}

are similar, not showing a high percentage of concordance between calculated and predicted wind directions. For Argyre (Table 7 ), we have found that $\sim 39 \%$ of the predictions at $50 \mathrm{~m}$ and at $1000 \mathrm{~m}$, and $20 \%$ of the predictions at the CPBL height agreed with the measurements. For Noachis (Table 8 ), we have found that $\sim 33 \%$ of the predictions at $50 \mathrm{~m}$ and at $1000 \mathrm{~m}$, and $\sim 31 \%$ of the predictions at the CPBL height agreed with the measurements. For Hellas (Table 9), we have found that $35 \%$ of the predictions at $50 \mathrm{~m}$ and at $1000 \mathrm{~m}$, and $\sim 25 \%$ of the predictions at the CPBL height agreed with the measurements. Finaly, we have found, for Eridania (Table 10), that $18 \%$ of the predictions at $50 \mathrm{~m}, \sim 22 \%$ at $1000 \mathrm{~m}$, and $\sim 27 \%$ of the predictions at the CPBL height agreed with the measurements. The diverging results for Argyre, when compared to those from Statella et al. (2014), are due to the coarser precision of the measured directions. In Statella et al. (2014) angular steps of $45^{\circ}$ were adopted, instead of $15^{\circ}$ used here. As the measurement details in the latter were coarser, the prevailing wind direction from the MCD in that case was considered to be the one showing a higher wind speed between N-S and EW components.

When we considered the whole set of 200 images, only $32 \%$, $33 \%$ and $25 \%$ of the extractions at $50 \mathrm{~m}, 1000 \mathrm{~m}$ and at the CPBL height, respectively, agreed with the dust devil tracks prevailing direction measurements. Table 11 summarizes the results for each quadrangle and also for the whole set of images.
In addition, we have extracted the surface wind stress using the MCD for the whole set of images. According to Haberle et al. (2003), a threshold stress of $0.0225 \mathrm{Nm}^{-2}$ would be needed to lift dust through bombardment from sand saltation. This has also been found to be true by Kahre et al. (2006), which used the NASA Ames general circulation model to investigate the mechanisms responsible for the observed martian dust cycle. According to their results, dust devil and wind stress lifting should both contribute to the simulated amount of dust found on the atmosphere. In our results, in none of the cases the large scale wind surface stress was higher than that threshold. The highest value we have found was $0.0108 \mathrm{Nm}^{-2}$, extracted from the MCD using the local time 16:00h, $\varphi \sim 54^{\circ} \mathrm{S}, \lambda \sim 13^{\circ} \mathrm{E}$ and $L_{s} \sim 182^{\circ}$. In such cases, the suction effect caused by the dust devils low-pressure cores must have assisted the wind stress in order to lift particles, as it has already been stated by Greeley et al. (1981), Greeley and Iversen (1985) and Greeley et al. (2003).

\section{Conclusions}

We have applied an automated method based on directional morphological openings to infer the prevailing dust devil tracks direction to a dataset of 200 images from Aeolis, Argyre, Eridania, Noachis and Hellas quadrangles. Next, we have compared the 
Table 10

Comparison between calculated prevailing wind direction and predicted wind direction for Eridania.

\begin{tabular}{|c|c|c|c|c|c|c|c|}
\hline \multirow[t]{2}{*}{ ID } & \multirow[t]{2}{*}{$L_{s}[$ deg.] } & \multirow[t]{2}{*}{ Local Time } & \multirow[t]{2}{*}{ Calculated [deg.] } & \multirow[t]{2}{*}{ CPBL $[\mathrm{m}]$} & \multicolumn{3}{|c|}{ Predicted [deg.] } \\
\hline & & & & & $50 \mathrm{~m}$ & $1000 \mathrm{~m}$ & CPBL \\
\hline E10-00563 & 265.98 & $14: 06$ & $105-285$ & 7200 & $120-300$ & $120-300$ & $105-285$ \\
\hline E09-02016 & 259.51 & $14: 16$ & $165-345$ & 6600 & $105-285$ & $105-285$ & $60-240$ \\
\hline R09-03051 & 266.28 & $14: 23$ & $150-330$ & 6700 & $15-195$ & $15-195$ & 15-195 \\
\hline R09-01707 & 261.74 & $14: 28$ & $150-330$ & 6600 & $30-210$ & $30-210$ & $30-210$ \\
\hline ESP_021874_1175_P1 & 262.80 & $15: 13$ & $135-315$ & 5700 & 15-195 & $0-180$ & $150-330$ \\
\hline ESP_021874_1175_P2 & 262.80 & $15: 13$ & $120-300$ & 5700 & 15-195 & $0-180$ & $150-330$ \\
\hline ESP_021874_1175_P3 & 262.80 & $15: 13$ & $105-285$ & 5700 & $15-195$ & $0-180$ & $150-330$ \\
\hline ESP_021939_1170 & 266.00 & $15: 10$ & $75-255$ & 6200 & $105-285$ & $120-300$ & $150-330$ \\
\hline ESP_021940_1205_P1 & 266.00 & $15: 07$ & $45-225$ & 5900 & $0-180$ & $165-345$ & $165-345$ \\
\hline ESP_021940_1205_P2 & 266.00 & $15: 07$ & $120-300$ & 5900 & $0-180$ & $165-345$ & $165-345$ \\
\hline ESP_021940_1205_P3 & 266.00 & $15: 07$ & $120-300$ & 5900 & $0-180$ & $165-345$ & $165-345$ \\
\hline PSP_004086_1180_P1 & 255.10 & $15: 25$ & $165-345$ & 5200 & $30-210$ & $30-210$ & $165-345$ \\
\hline PSP_004086_1180_P2 & 255.10 & $15: 25$ & $60-240$ & 5200 & $30-210$ & $30-210$ & $165-345$ \\
\hline PSP_004086_1180_P3 & 255.10 & $15: 25$ & $45-225$ & 5200 & $30-210$ & $30-210$ & $165-345$ \\
\hline E10-04027 & 278.89 & $14: 02$ & 15-195 & 7000 & $0-180$ & $0-180$ & $0-180$ \\
\hline E11-01652 & 287.74 & $13: 46$ & $30-210$ & 6500 & $165-345$ & $0-180$ & $30-210$ \\
\hline E11-01664 & 287.79 & $13: 53$ & $0-180$ & 7200 & $0-180$ & $0-180$ & $0-180$ \\
\hline E11-02785 & 292.18 & $13: 46$ & $165-345$ & 6800 & $0-180$ & $0-180$ & $0-180$ \\
\hline E11-02787 & 292.18 & $13: 45$ & $0-180$ & 6500 & $0-180$ & $0-180$ & $0-180$ \\
\hline E11-02045 & 289.04 & $13: 40$ & $0-180$ & 6000 & $165-345$ & $165-345$ & $120-300$ \\
\hline R09-04267_P1 & 270.71 & $14: 16$ & $60-240$ & 6300 & $105-285$ & $105-285$ & $45-225$ \\
\hline R09-04267_P2 & 270.71 & $14: 16$ & $150-330$ & 6300 & $105-285$ & $105-285$ & $45-225$ \\
\hline R10-04120 & 285.52 & $14: 07$ & $135-315$ & 7700 & $0-180$ & $0-180$ & $0-180$ \\
\hline R11-02327 & 298.55 & $13: 50$ & $45-225$ & 6000 & $30-210$ & $30-210$ & $0-180$ \\
\hline R10-03758 & 284.16 & $14: 10$ & $135-315$ & 6800 & $165-345$ & $165-345$ & $0-180$ \\
\hline R10-02441 & 279.70 & $14: 15$ & $165-345$ & 6800 & $165-345$ & $165-345$ & $165-345$ \\
\hline R10-03959_P1 & 284.82 & $14: 10$ & $120-300$ & 6600 & $165-345$ & $165-345$ & $0-180$ \\
\hline R10-03959_P2 & 284.82 & $14: 10$ & $120-300$ & 6600 & $165-345$ & $165-345$ & $0-180$ \\
\hline R10-04815 & 287.98 & $14: 06$ & 15-195 & 6700 & $165-345$ & $165-345$ & $0-180$ \\
\hline R10-03563_P1 & 283.55 & $14: 12$ & $45-225$ & 6400 & $165-345$ & $165-345$ & $0-180$ \\
\hline R10-03563_P2 & 283.55 & $14: 12$ & $135-315$ & 6400 & $165-345$ & $165-345$ & $0-180$ \\
\hline R11-02811 & 299.83 & $13: 51$ & $0-180$ & 6800 & $135-315$ & $135-315$ & $0-180$ \\
\hline E11-04510 & 300.81 & $13: 36$ & $165-345$ & 6100 & 120 & $135-315$ & $0-180$ \\
\hline R12-00250 & 309.59 & $13: 43$ & $30-210$ & 6200 & $105-285$ & $120-300$ & $0-180$ \\
\hline R12-02283 & 319.06 & $13: 40$ & 15-195 & 5800 & $90-270$ & $105-285$ & $165-345$ \\
\hline PSP_005510_1290 & 322.40 & $14: 25$ & $0-180$ & 6200 & $60-240$ & $75-255$ & $120-300$ \\
\hline ESP_023021_1160_P1 & 317.10 & $14: 30$ & $90-270$ & 5300 & $120-300$ & $135-315$ & $150-330$ \\
\hline ESP_023021_1160_P2 & 317.10 & $14: 30$ & $75-255$ & 5300 & $120-300$ & $135-315$ & $150-330$ \\
\hline ESP_023021_1160_P3 & 317.10 & $14: 30$ & $90-270$ & 5300 & $120-300$ & $135-315$ & $150-330$ \\
\hline ESP_023021_1160_P4 & 317.10 & $14: 30$ & $105-285$ & 5300 & $120-300$ & $135-315$ & $150-330$ \\
\hline ESP_023021_1160_P5 & 317.10 & $14: 30$ & $105-285$ & 5300 & $120-300$ & $135-315$ & $150-330$ \\
\hline ESP_023021_1160_P6 & 317.10 & $14: 30$ & $75-255$ & 5300 & $120-300$ & $135-315$ & $150-330$ \\
\hline ESP_014121_1180 & 313.30 & $14: 38$ & $150-330$ & 6600 & $165-345$ & $165-345$ & $150-330$ \\
\hline R13-01492 & 331.07 & $13: 48$ & $15-195$ & 5100 & $45-225$ & $45-225$ & $120-300$ \\
\hline PSP_006248_1235 & 353.20 & $14: 34$ & $0-180$ & 5100 & $105-285$ & $105-285$ & $105-285$ \\
\hline
\end{tabular}

Table 11

Summary of the results for the comparison between measured and predicted wind directions for each of the quadrangles and for the whole set of images.

\begin{tabular}{lllll}
\hline & $\begin{array}{l}\text { Number } \\
\text { of images }\end{array}$ & \multicolumn{2}{l}{ Altitude } & \\
\cline { 3 - 5 } & & $\mathbf{5 0} \mathbf{~ m}$ & $\mathbf{1 0 0 0} \mathbf{~ m}$ & $\mathbf{C P B L}$ \\
\hline Aeolis & 5 & $20 \%$ & $20 \%$ & $20 \%$ \\
Argyre & 71 & $39 \%$ & $39 \%$ & $20 \%$ \\
Noachis & 39 & $33 \%$ & $33 \%$ & $31 \%$ \\
Hellas & 40 & $35 \%$ & $35 \%$ & $25 \%$ \\
Eridania & 45 & $18 \%$ & $22 \%$ & $27 \%$ \\
For the whole dataset & 200 & $32 \%$ & $33 \%$ & $25 \%$ \\
\hline
\end{tabular}

inferred directions with the MCD predicted wind directions for different altitudes from the surface: $50 \mathrm{~m}, 1000 \mathrm{~m}$ and at the CPBL height. In all cases the accordance between measurements and predictions is low. In the best case (for $1000 \mathrm{~m}$ above the surface), this value reaches $33 \%$, considering a tolerance of $15^{\circ}$ (the angular steps adopted when measuring dust devil tracks directions). All the results are very similar, with the prediction performed using the CPBL height giving the worst agreement with the dust devil tracks prevailing direction measurements. Taken individually, none of the quadrangles showed a conformity between measured and predicted directions higher than $39 \%$. This seems to be a good indicator that the MCD fails to predict local wind patterns, such as the ones driving dust devil vortices on the surface of Mars, perhaps due to an insufficient resolution. Therefore, for a more local scale, the dominant wind direction should be inferred preferably by methods other than the MCD simulations, namely from the analysis of the dust devil tracks prevailing orientations. For that purpose, we intend to perform a systematic collection of image data showing dust devil tracks, specifically from several representative sites in several time periods, aided by recent platforms that facilitate checking about the availability of multi-temporal imagery of high resolution in order to quantify the changes of these dynamic surface processes on Mars (Sidiropoulos and Muller, 2015; Erkeling et al., 2016).

In addition, the extractions for the surface wind stress at each scene center coordinates was never higher than the threshold stress of $0.0225 \mathrm{Nm}^{-2}$ needed to lift dust even though there are dust devil tracks. It agrees with results from Greeley et al. (1981), Greeley and Iversen (1985) and Kahre et al. (2006) and reinforces 
that dust devil vortices, as well as other mechanisms such as slope winds (Rafkin et al., 2002) and rocket dust storms (Spiga et al., 2013), are important actors in lifting dust particles, contributing to the local atmosphere opacity and surface modification.

\section{References}

Balme, M.R., Greeley, R., 2006. Dust devils on Earth and Mars. ReviewsofGeophysics 44, RG3003.

Balme, M.R., Whelley, P.L., Greeley, R., 2003. Mars: dust devil track survey in Argyre Planitia and Hellas Basin. J. Geophys. Res. 108 (E8).

Erkeling, G., Luesebrink, D., Hiesinger, H., Reiss, D., Heyer, T., Jaumann, R., 2016. The Multi-Temporal Database of Planetary Image Data (MUTED): A database to support the identification of surface changes and short-lived surface processes. Planet. SpaceSci. http://dx.doi.org/10.1016/j.pss.2016.03.002

Fenton, L.K., Lorenz, R., 2015. Dust devil height and spacing with relation to the martian planetary layer thickness. Icarus 260, 246-262.

Forget, F., Hourdin, F., Fournier, R., Hourdin, C., Talagrand, O., Collins, M., Lewis, S.R , Read, P.L., Huot, J.-P., 1999. Improved general circulation models of the martian atmosphere from the surface to above $80 \mathrm{~km}$. J. Geophys. Res. 104 (E10), 24155-24175.

Greeley, R., Iversen, J., 1985. Wind as a Geologic Process on Earth, Mars, Venus and Titan. Cambridge Univ. Press, New York.

Greeley, R., White, B., Pollack, J.B., Iversen, J., Leach, R.N., 1981. Dust storms on Mars: Considerations and simulations, in Desert Dust: Origin, Characteristics, and Effect on Man edited by T. Péwé. Spec. Pap. Geol. Soc. Am 186, 101-121.

Greeley, R., et al., 2003. Martian dust devils: Laboratory simulations of particle threshold. J. Geophys. Res. 108, E5.

Haberle, R., Houben, H., Hertenstein, R., Herdtle, T., 1993. A boundary layer model for Mars: Comparison with Viking lander and entry data. J. Atmos. Sci. 50, 1544-1559.

Haberle, M.H., Murphy, J.R., Schaeffer, J., 2003. Orbital change experiments with a Mars general circulation model. Icarus 161, 66-89.

Hinson, D.P., Pätzold, M., Tellmann, S., Häusler, B., Tyler, G.L., 2008. The depth of the convective boundary layer on Mars. Icarus 198, 57-66.

Kahre, M.A., Murphy, J.R., Haberle, R.M., 2006. Modeling the Martian dust cycle and surface dust reservoirs with the NASA Ames general circulation model. J. Geophys. Res. Planets 111, 10.1029/2005je002588.
Lewis, S.R., Collins, M., Read, P.L., Forget, F., Hourdin, F., Fournier, R., Hourdin, C., Talagrand, O., Huot, J.P., 1999. A climate database for Mars. J. Geophys. Res. Planets 104, E10.

Malin, M.C., Edgett, K.S., 2001. Mars Global Surveyor Mars Orbiter Camera: interplanetary cruise through primary mission. J. Geophys. Res. 106, E10.

Petrosyan, A., Galperin, B., Larsen, S.E., Lewis, S.R., Määttänen, A., Read, P.L., Renno, N., Rogberg, L.P.H.T., Savijärvi, H., Siili, T., Spiga, A., Toigo, A., Vázquez, L., 2011. The Martian armospheric boundary layer. ReviewsofGeophysics 49, RG3005. http://dx.doi.org/10.1029/2010RG000351.

Rafkin, S.C.R., Maria, M.R.V.S., Michaels, T.I., 2002. Simulation of the atmospheric thermal circulation of a martian volcano using a mesoscale numerical model Nature 419, 697-699.

Rennó, N.O., Burkett, M.L., Larkin, M.P., 1998. A simple thermodynamical theory for dust devils. J. Atmos. Sci. 55, 3244-3252.

Sidiropoulos, P. Muller, J.-P., 2015. On the status of orbital high-resolution repeat imaging of Mars for the observation of dynamic surface processes. Planet. SpaceSci. 117, 207-222.

Soille, P., 2004. Morphological Image Analysis. Springer-Verlag, Berlin.

Spiga, A., Faure, J., Madeleine, J.B., Maatanen, A., Forget, F., 2013. Rocket dust storms and detached dust layers in the martian atmosphere. J. Geophys. Res. ((Planets)) 118, 746-767.

Statella, T., Pina, P., Silva, E.A., 2012. Image processing algorithm for the identification of Martian dust devil tracks in MOC and HiRISE images. Planet. Space. Sci. 70, 46-58.

Statella, T., Pina, P., Silva, E.A., 2014. Automated determination of the orientation of dust devil tracks in Mars orbiter images. Adv. SpaceRes. 53, 1822-1833.

Statella, T., 2015. Mapping Mars: Geodetic and cartographic aspects. Planet. SpaceSci. 108, 1-12.

Statella, T., Pina, P., Silva, E.A., 2015. Extensive computation of albedo contrast between Martian dust devil tracks and their neighboring regions. Icarus 250, $43-52$.

Statella, T., Pina, P., Silva, E.A., 2016. Automated width measurements of Martian dust devil tracks. AeolianResearch 20, 1-6.

Thomas, P.C., Gierasch, P., Sullivan, R., Miller, D.S., Cartillo, E.A., Cantor, B., Mellon, M.T., 2003. Mesoscale linear streaks on Mars: environments of dust entrainment. Icarus 162, 242-258.

Whelley, P., Greeley, R., 2006. Latitudinal dependency in dust devil activity on Mars. J. Geophys. Res. 111, E10003. 